\title{
SiO2 Glass Density to Lower-Mantle Pressures
}

Petitgirard, Sylvain; Malfait, Wim J.; Journaux, Baptiste; Collings, Ines E.; Jennings, Eleanor S.; Blanchard, Ingrid; Kantor, Innokenty; Kurnosov, Alexander; Cotte, Marine; Dane, Thomas Total number of authors:

12

Published in:

Physical Review Letters

Link to article, DOI:

10.1103/PhysRevLett.119.215701

Publication date:

2017

Document Version

Publisher's PDF, also known as Version of record

Link back to DTU Orbit

Citation (APA):

Petitgirard, S., Malfait, W. J., Journaux, B., Collings, I. E., Jennings, E. S., Blanchard, I., Kantor, I., Kurnosov, A., Cotte, M., Dane, T., Burghammer, M., \& Rubie, D. C. (2017). SiO2 Glass Density to Lower-Mantle Pressures. Physical Review Letters, 119(21), [215701]. https://doi.org/10.1103/PhysRevLett.119.215701

\section{General rights}

Copyright and moral rights for the publications made accessible in the public portal are retained by the authors and/or other copyright owners and it is a condition of accessing publications that users recognise and abide by the legal requirements associated with these rights.

- Users may download and print one copy of any publication from the public portal for the purpose of private study or research.

- You may not further distribute the material or use it for any profit-making activity or commercial gain

- You may freely distribute the URL identifying the publication in the public portal 


\title{
$\mathrm{SiO}_{2}$ Glass Density to Lower-Mantle Pressures
}

\author{
Sylvain Petitgirard, ${ }^{1, *}$ Wim J. Malfait, ${ }^{2}$ Baptiste Journaux,${ }^{3}$ Ines E. Collings, ${ }^{4,6}$ Eleanor S. Jennings, ${ }^{1}$ \\ Ingrid Blanchard, ${ }^{1}$ Innokenty Kantor, ${ }^{5}$ Alexander Kurnosov, ${ }^{1}$ Marine Cotte, ${ }^{6,7}$ Thomas Dane, ${ }^{6}$ \\ Manfred Burghammer, ${ }^{6}$ and David C. Rubie ${ }^{1}$ \\ ${ }^{1}$ Bayerisches Geoinstitut, University of Bayreuth, Bayreuth D-95440, Germany \\ ${ }^{2}$ Laboratory for Building Energy Materials and Components, Swiss Federal Laboratories for Materials Science and Technology, \\ Empa, 8600 Dübendorf, Switzerland \\ ${ }^{3}$ Institut des Géosciences de l'Environnement-UMR 5001, \\ Université Grenoble Alpes CS 40700, 38058 Grenoble Cedex 9, France \\ ${ }^{4}$ Laboratory of Crystallography, University of Bayreuth, Bayreuth D-95440, Germany \\ ${ }^{5}$ Danmarks Tekniske Universitet, 2800 Kgs. Lyngby, Denmark \\ ${ }^{6}$ European Synchrotron Radiation Facility, BP 220, Grenoble F-38043, France \\ ${ }^{7}$ Sorbonne Universités, UPMC Univ Paris 06, CNRS, UMR 8220, Laboratoire d'archéologie moléculaire et structurale (LAMS), \\ 4 Place Jussieu 75005 Paris, France
}

(Received 22 November 2016; revised manuscript received 7 August 2017; published 21 November 2017)

\begin{abstract}
The convection or settling of matter in the deep Earth's interior is mostly constrained by density variations between the different reservoirs. Knowledge of the density contrast between solid and molten silicates is thus of prime importance to understand and model the dynamic behavior of the past and present Earth. $\mathrm{SiO}_{2}$ is the main constituent of Earth's mantle and is the reference model system for the behavior of silicate melts at high pressure. Here, we apply our recently developed x-ray absorption technique to the density of $\mathrm{SiO}_{2}$ glass up to $110 \mathrm{GPa}$, doubling the pressure range for such measurements. Our density data validate recent molecular dynamics simulations and are in good agreement with previous experimental studies conducted at lower pressure. Silica glass rapidly densifies up to $40 \mathrm{GPa}$, but the density trend then flattens to become asymptotic to the density of $\mathrm{SiO}_{2}$ minerals above $60 \mathrm{GPa}$. The density data present two discontinuities at $\sim 17$ and $\sim 60 \mathrm{GPa}$ that can be related to a silicon coordination increase from 4 to a mixed 5/6 coordination and from 5/6 to sixfold, respectively. $\mathrm{SiO}_{2}$ glass becomes denser than $\mathrm{MgSiO}_{3}$ glass at $\sim 40 \mathrm{GPa}$, and its density becomes identical to that of $\mathrm{MgSiO}_{3}$ glass above $80 \mathrm{GPa}$. Our results on $\mathrm{SiO}_{2}$ glass may suggest that a variation of $\mathrm{SiO}_{2}$ content in a basaltic or pyrolitic melt with pressure has at most a minor effect on the final melt density, and iron partitioning between the melts and residual solids is the predominant factor that controls melt buoyancy in the lowermost mantle.
\end{abstract}

DOI: 10.1103/PhysRevLett.119.215701

The concentration of $\mathrm{SiO}_{2}$ exceeds 45 mole \% in the Earth's mantle [1], and has a primary role in the properties of minerals and melts at mantle conditions. The $\mathrm{SiO}_{2}$ reference system is therefore of great importance for constraining the density, compressibility, and atomic coordination changes of the more complex silicate melt compositions that can be found in the deep interior of Earth and other rocky planets $[2,3]$. Studies of the high-pressure ( $>25 \mathrm{GPa}$ ) properties of simple silicate melts, e.g., $\mathrm{MgO}, \mathrm{SiO}_{2}$, and $\mathrm{Al}_{2} \mathrm{O}_{3}$, are scarce, because of high melting temperatures [4,5], and also because of their insulating character (high-band gap) that prohibits the use of the standard YAG laser-heating system in diamond anvil cell (DAC). In addition, glasses and melts made of light elements (with low atomic mass) produce a weak x-ray scattering signal that is difficult to extract from the background of the diamond anvils. In contrast, the x-ray absorption method enables the study of melts [6,7], and glasses [8] composed of light elements, because it retains its sensitivity also for light elements, and the data interpretation is straightforward.
Generating high pressure and temperature conditions limit the accuracy and diversity of analytical techniques for in situ melt studies. Investigations on glasses as melt proxies can circumvent these limitations, but it is important to account for differences between glasses and melts and their comparison requires some caution. In the liquid state, structural equilibration is faster than the external perturbations, and the properties of the melt rapidly relax to new pressure or temperature conditions $[9,10]$. During cooling of the melt, the rate of equilibration slows down and, assuming crystallization is avoided, the structure is frozen at the glass transition [11]. The divide between the liquid and glassy state depends not only on temperature, but also on the frequency of the probe. Ultrasonic measurements of high temperature melts can sample both the elastic and configurational compressibility $[12,13]$, but Brillouin scattering only probes the elastic compressibility [14]. Cold compression experiments on glasses represent an intermediate case: although the structure and properties are not in equilibrium, significant configurational changes undoubtedly take place 
upon compression to lower mantle pressure $[8,15,16]$ and strong similarities exist between the structure of a high pressure glass and melt, most notably with respect to $\mathrm{Si}$ coordination $[2,8,15-18]$.

At ambient pressure, $\mathrm{SiO}_{2}$ glass has a fully polymerized structure, with silicon atoms coordinated with four oxygen atoms to form corner-sharing $\mathrm{SiO}_{4}$ tetrahedrons. The structure contains nominally no non-bridging oxygens (NBO) per tetrahedron $(T)(\mathrm{NBO} / T=0)$, meaning that each oxygen atom connects two silicon atoms forming a network of silica tetrahedra. The incorporation of network modifiers, such as magnesium oxide, increases the number of nonbridging oxygens per tetrahedron, e.g., nominal $\mathrm{NBO} / T=2$ for $\mathrm{MgSiO}_{3}$. Note that the concept of $\mathrm{NBO} / T$ breaks down at high pressure once $\mathrm{Si}$ increases its coordination at the expense of NBO; i.e., NBO decreases and $T$ decreases. At ambient pressure, $\mathrm{SiO}_{2}$ glass density is lower than expected from the atomic weights of its constituents, because of a relatively open structure [19-21]. Although brittle at a macroscopic scale at ambient conditions, $\mathrm{SiO}_{2}$ glass can deform elastically and reversibly up to $9 \mathrm{GPa}$ [22]. Above this elastic yield pressure, the recovered pressurized glass shows signs of a permanent densification through plastic deformation [23-26], which saturates at about $25 \mathrm{GPa}$ $[22,27]$. The in situ density of $\mathrm{SiO}_{2}$ glass under compression follows a steep, approximately linear trend up to $35-40 \mathrm{GPa}$, but the rate of densification becomes less steep at higher pressures $[8,28]$. Under large pressure gradients, $\mathrm{SiO}_{2}$ glass shows variable strength related to changes of coordination and/or degree of depolymerization [29].

Understanding the properties of the fully polymerized $\mathrm{SiO}_{2}$ network with pressure is essential to simulate and predict the role and influence of cation network modifiers in high-pressure melts of the deep Earth. Here we measured the density of pure $\mathrm{SiO}_{2}$ glass up to $110 \mathrm{GPa}$ using the x-ray absorption method adapted to the environment of the DAC [30] and use the glass data to estimate the density of the corresponding melts. Our results show that the density of $\mathrm{SiO}_{2}$ and $\mathrm{MgSiO}_{3}$ glass and melt are very similar at high pressure and we conclude that the main factor controlling melt buoyancy in the lowermost mantle is the partitioning of iron between the melt and coexisting mineral phases, with at most a minor role for the silica content of the melt.

$\mathrm{X}$-ray absorption measurements were performed on the ID13 (nano branch) and on the ID21 (side branch) [31] beam lines at the European Synchrotron Radiation Facility (ESRF, Grenoble, France) (Fig. S1A-C [32]). Samples were loaded in BX90 DACs [33] and the pressure was determined from the shift of the ruby fluorescence [34] or diamond line [35] (details in the Supplemental Material [32]). The measurement procedure is the same as for $\mathrm{MgSiO}_{3}$ glass [30] with 2D mapping of the sample under two orientations: (i) through the diamond to obtain the path length $(x)$ of the $\mathrm{x}$ rays through the $\mathrm{SiO}_{2}$ sample [Figs. 1(a)-1(b) and Figs. S2A-B in the Supplemental Material [32]] and (ii) through the Be gasket in order to measure the x-ray attenuation $\left(I / I_{0}\right)$ of

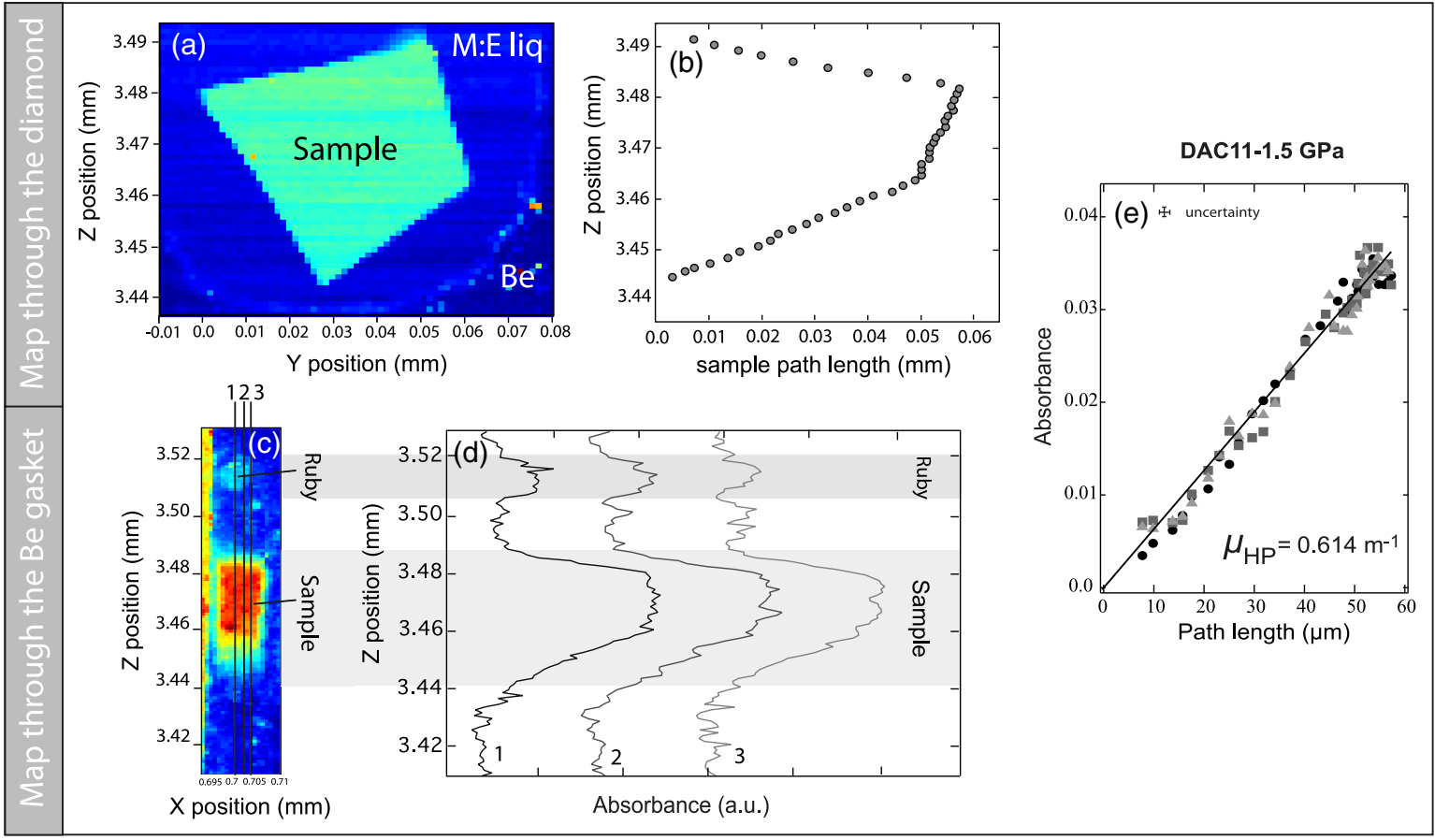

FIG. 1. Low-pressure run with a double polished $\mathrm{SiO}_{2}$ plate immersed in a methanol:ethanol mixture. (a)-(b) Map through the diamonds to determine the path length $(x)$. (c)-(d) Absorption map through the Be gasket (showing three profiles in black, gray, and light gray). (e) Correlation between (b) and (d) gives the linear absorbance of the sample [colors of the symbols refers to the different correlations with the three different profiles of $(c-d)]$. 
$\mathrm{SiO}_{2}$ glass under pressure [Figs. 1(c)-1(d) and Fig. S2C-D in the Supplemental Material [32]]. The edges of the sample, defining the path length $(x)$, can be obtained with a precision better than $1 \mu \mathrm{m}$, corresponding to an uncertainty of about $2 \%$ on the density. The absorbance $\left(\mu_{\mathrm{HP}}\right)$ of the sample was extracted from the correlation between the x-ray attenuation and the path length of the sample obtained from both maps [Fig. 1(e) and Fig. S2E in the Supplemental Material]. The slope of the linear regression gives the linear absorbance at high pressure $\left(\mu_{\mathrm{HP}}\right)$ through the Beer-Lambert relation:

$$
\ln \left(I / I_{0}\right)=-\mu_{\mathrm{HP}} x .
$$

The density at high pressure ( $\left.\rho_{\mathrm{HP}}\right)$ was then calculated by

$$
\rho_{\mathrm{HP}} / \mu_{\mathrm{HP}}=\rho_{0} / \mu_{0} .
$$

The attenuation coefficient at ambient pressure $\left(\mu_{0}\right)$ was determined from the absorption of a double-polished plate of $\mathrm{SiO}_{2}$ using the same setup on the beam line, and the ambient pressure density $\left(\rho_{0}\right)$ of Suprasil silica glass is $2.203 \pm 0.008 \mathrm{~g} / \mathrm{cm}^{3}$. Our density measurements on $\mathrm{SiO}_{2}$ glass were performed between 2 and $110 \mathrm{GPa}$, doubling the former pressure range [8] [Fig. 2(a)]. Our data are in good agreement with previous experimental results $[8,28]$, as well as with densities predicted from ab initio molecular dynamics (MD) calculations [Fig. 2(a)] [18]. The density of $\mathrm{SiO}_{2}$ glass can be separated into three pressure regimes based on different compressibility trends, as evidenced by the f-F plot [Fig. 2(b)] in the Vinet form [36]. Although it is less evident when using the Eulerian definition [37] (Fig. S3 [32]), two domains are also visible. First, we identify a steep and quasilinear increase in density up to $\sim 17 \mathrm{GPa}$, followed by a curvature of the trend between 17 and $60 \mathrm{GPa}$ with a decrease of the compressibility as a function of pressure, and, finally, a flattening and asymptotic trend to the density of the $\mathrm{SiO}_{2}$ stishovite and the $\mathrm{CaCl}_{2}$ phases [38,39] above $60 \mathrm{GPa}$ [Fig. 2(a)]. The data set cannot be described by a single equation of state (EOS), third or fourth order Birch-Murnghan (BM) [Fig. S4A-B in the Supplemental Material [32]]. Instead, the three domains identified in the pressure-density data and $\mathrm{f}-\mathrm{F}$ plot [Figs. 2(a)-2(b)] suggest that distinct compression mechanisms are dominant for the different pressure domains, related to the Si coordination. Our interpretation is based on MD simulations [18] that show almost exclusively ${ }^{[4]} \mathrm{Si}$ below $\sim 17 \mathrm{GPa}$, a rapid decrease of ${ }^{[4]} \mathrm{Si}$ starting around $\sim 20 \mathrm{GPa},{ }^{[5]} \mathrm{Si}$ as the dominant species mixed with ${ }^{[6]} \mathrm{Si}$ between 20 and $60 \mathrm{GPa}$, and the abrupt near disappearance of ${ }^{[5]} \mathrm{Si}$ in favor of ${ }^{[6]} \mathrm{Si}$ at $\sim 60 \mathrm{GPa}$ and no further major structural changes up to $\sim 140 \mathrm{GPa}$ [40]. The lack of longrange order and multiple coordination lead to gradual structural transitions explaining the lack of abrupt changes in the compression curve [Fig. 2(a)]. The pressure ranges for the different species are in very good agreement with
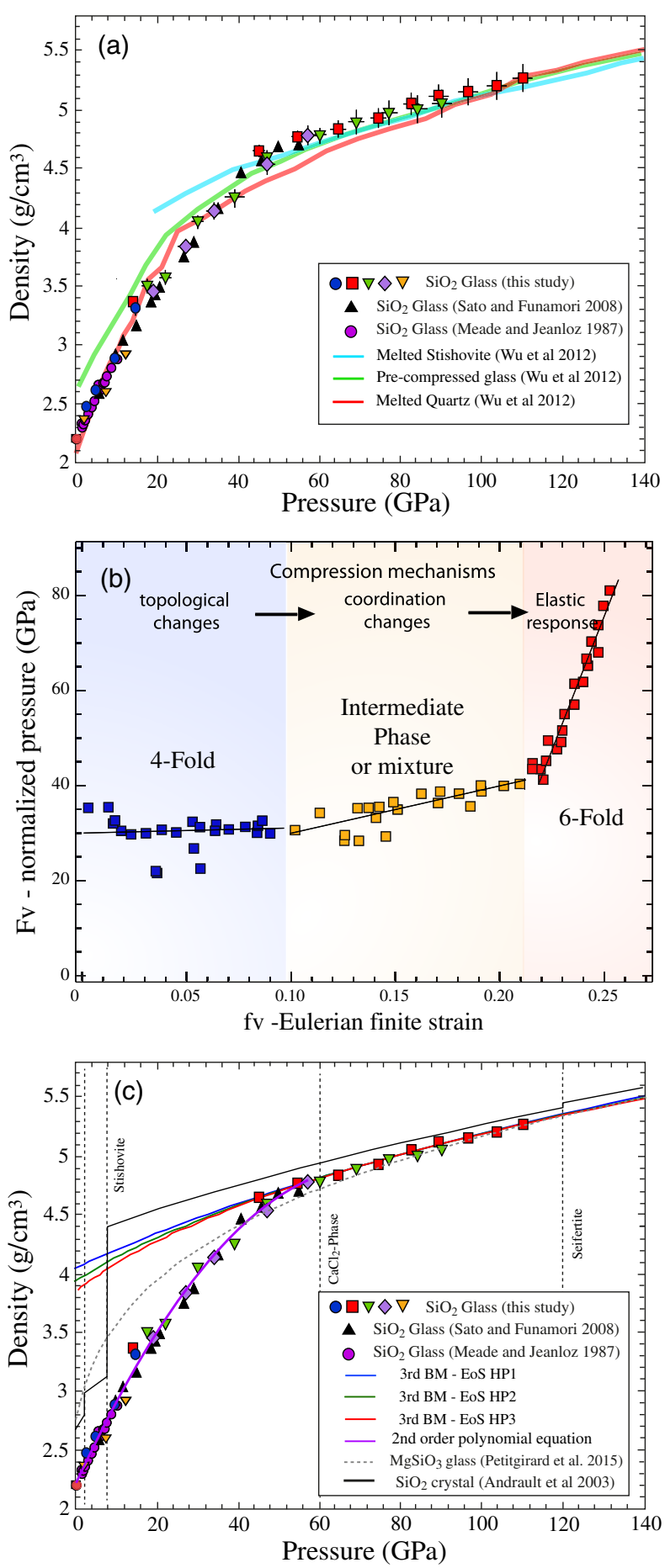

FIG. 2. $\mathrm{SiO}_{2}$ glass density at high pressure. (a) Density measured in this study (one colours per loading) compared to previous experimental $[16,17]$ and simulation [18] data. (b) Strain vs normalized pressure (f-F) plot from the Vinet description [36]. Black lines are guides to the eye. (c) Equations of state for the two pressure domains: from 0 to $60 \mathrm{GPa}$ using a second order polynomial; above $60 \mathrm{GPa}$ three EOS are used to fit the data (HP1, HP2, and HP3 see text and Table S2 [32]). The black line represents the density of $\mathrm{SiO}_{2}$ polymorphs [38,39]. The dashed line is the $\mathrm{MgSiO}_{3}$ glass density [30]. 
our data and provide a framework to explain the density and compressibility trends in $\mathrm{SiO}_{2}$ glass, but further investigations are required. Interestingly, the compression curve for $\mathrm{MgSiO}_{3}$ glass does not display the distinct pressure domains observed for $\mathrm{SiO}_{2}$ glass, and a single EOS can be used from 0 to $130 \mathrm{GPa}$ [30]. The depolymerized nature of $\mathrm{MgSiO}_{3}$ glass may allow the structure to approach quasiequilibrium densities, i.e., more meltlike configurations, upon compression, whereas the highly polymerized $\mathrm{SiO}_{2}$ structure involves crossing higher potential energy barriers. This is supported by the existence of much larger irreversible densifications for $\mathrm{SiO}_{2}$ glass [26] compared to $\mathrm{MgSiO}_{3}$ glass [41] and consistent with the role of nonbridging oxygens in facilitating $\mathrm{Si}$ coordination increases [42]. For the high pressure regime $(P>60 \mathrm{GPa})$ where $\mathrm{Si}$ coordination changes are absent $[8,18,40,43]$, or minor [44], configurational contributions to the compressibility for both glass and melt is expected to be minimal, and above this pressure, $\mathrm{SiO}_{2}$ melt may behave in a similar way as the glass.

Common EOS such as the Birch-Murnaghan or Vinet are of limited theoretical validity for glasses and melts, where densification occurs for a large part through configurational changes. However, they can provide an empirical means to interpolate between data but extrapolations far beyond the experimental data should be avoided. Given the occurrence of distinct pressure domains [Figs. 2(a)-2(b)], a fit with a single EoS for the entire pressure range is not appropriate (SI, Fig. S4). The $\mathrm{f}-\mathrm{F}_{\mathrm{V}}$ plot identified a distinct regime above $\sim 60 \mathrm{GPa}$ [Fig. 2(b)], where the coordination of $\mathrm{Si}$ remains constant $\left({ }^{[6]} \mathrm{Si}\right)[18]$ and close densities to that of the crystalline $\mathrm{SiO}_{2}$ phases, suggesting a single compression mechanism above $60 \mathrm{GPa}$. The positive and linear slope in both f-F plots [Fig. 2(b) and Supplemental Material, Fig. S3 [32]] indicates that a 3rd order BM EOS with a $K_{\mathrm{T}}^{\prime}>4$ is appropriate. We used 3rd order BM EOS fits with bulk modulus derivatives $\left(K_{\mathrm{HP}, T 0}^{\prime}\right)$ fixed at 4, 5, and 6, named $\mathrm{HP}$, HP2, and HP3 [Table S2 [32] and Fig. 2(c)]. Fixing $K_{\mathrm{HP} 1, T 0}^{\prime}$ at 4 results in a high bulk modulus $\left(K_{\mathrm{HP} 1, T 0}=244.7 \mathrm{GPa}\right)$ and a density $\rho_{\mathrm{HP} 1, T 0}=4.05 \mathrm{~g} \cdot \mathrm{cm}^{-3}$. When $K_{\mathrm{HP} 2, T 0}^{\prime}$ is fixed at 5 or $K_{\mathrm{HP} 3, T 0}=6, K_{\mathrm{HP} 2, T 0}$ decreases to 183.3 and $K_{\mathrm{HP} 3, T 0}=138 \mathrm{GPa}$, with $\rho_{\mathrm{HP} 2, T 0}=3.95$ and $\rho_{\mathrm{HP} 3, T 0}=$ $3.85 \mathrm{~g} / \mathrm{cm}^{3}$, respectively. The different values for the EOS are quite similar to previous estimates [8], but are now more robust as we used a larger pressure range. The differences between the EOS for different $K_{\mathrm{HP}, T 0}^{\prime}$ reside mostly in $\rho_{0}$, with minimal variations upon extrapolation to higher pressures [Fig. 2(c)]. In the discussion below, we use the values of HP2 EOS (Table S2 [32]).

For the low-pressure domain $(<60 \mathrm{GPa})$, the scattering of the points in the f-F plot using the eulerian definition with a negative slope (Fig. S3 in the Supplemental Material [32]) suggest that a classical EOS might not be appropriate. Indeed, a 4th order BM EOS with $\rho_{0}=2.200 \mathrm{~g} \mathrm{~cm}^{-3}$,
$K_{T 0}=27.6 \pm 3.2 \mathrm{GPa}, K_{T 0}^{\prime}=1.95 \pm 0.52$, and $K_{T 0}^{\prime \prime}=$ $-0.098 \pm 0.021 \mathrm{GPa}^{-1}$ reproduces the data, but the values for $K_{T 0}^{\prime}$ and $K_{T 0}^{\prime \prime}$ are not realistic. The low pressure data may be further split into two domains as suggested by the $\mathrm{f}-\mathrm{F}_{\mathrm{V}}$ plot in Fig. 2(b), but we have opted to use a 2nd order polynomial function as proposed elsewhere for data not satisfying the Birch's law [45], with

$$
\begin{aligned}
\rho= & -0.00053802( \pm 94) P^{2} \\
& +0.076204( \pm 42) P+2.203,
\end{aligned}
$$

where $\rho$ is expressed in $\mathrm{g} / \mathrm{cm}^{3}$ and $P$ in GPa (Fig. S5 in the Supplemental Material [32]). The difficulty to fit a classical EOS arises from the occurrence of multiple densification mechanisms, with topological changes below $\sim 17 \mathrm{GPa}$ and an increase in $\mathrm{Si}$ coordination with mixed $\mathrm{Si}$ coordination at higher pressure [18]. The fact that the starting $\mathrm{SiO}_{2}$ glass is a two-phase mixture, with a high-density amorphous (HDA) and low-density amorphous (LDA) phase [46], may further complicate the use of a classical EOS. However, we cannot rule out that the melt will be composed of a single phase in the low-pressure regime, and it can reach an equilibrated structure below $60 \mathrm{GPa}$.

The experimentally determined density of $\mathrm{SiO}_{2}$ glass crosses over with the one of $\mathrm{MgSiO}_{3}$ at about $40 \mathrm{GPa}$ [Fig. 2(c)]. The densities of both compositions converge at higher pressure, above $~ 90 \mathrm{GPa}$ [Fig. 2(c), Fig. 3], and remain nearly equal at all higher pressure studied here and probably up to core-mantle boundary $(\mathrm{CMB})$ pressure following our extrapolation [Fig. 2(c), Fig. 3]. From our EOS at $300 \mathrm{~K}$ for $\mathrm{SiO}_{2}$ for the deep mantle $(\mathrm{P}>60 \mathrm{GPa})$, we calculated densities along an isotherm at $4000 \mathrm{~K}$ (Fig. 3)

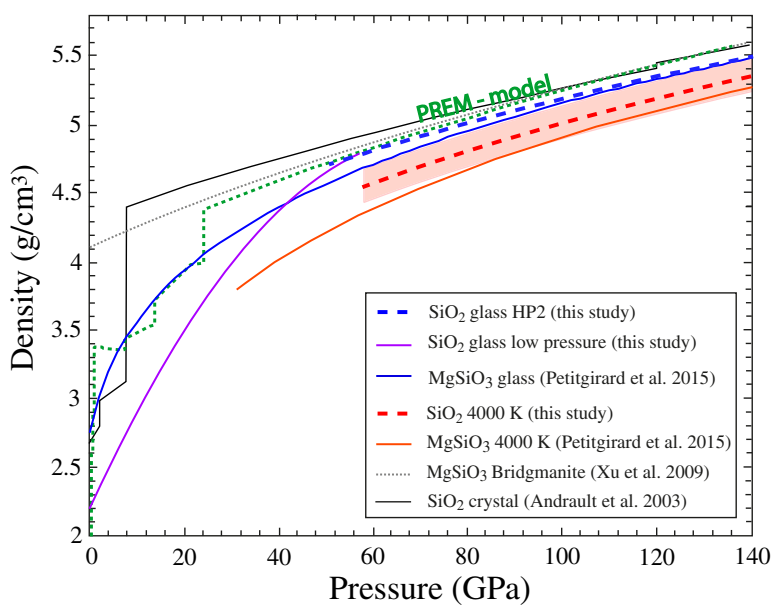

FIG. 3. $\mathrm{SiO}_{2}$ density at room and high temperature. $\mathrm{SiO}_{2}$ and $\mathrm{MgSiO}_{3}$ [30] glass density at room temperature in dashed and continuous blue lines, respectively. In red, densities to lowermantle temperatures of $4000 \mathrm{~K}$. Density for $\mathrm{SiO}_{2}$ crystals [38,39], bridgmanite [49], and the PREM model [50] are plotted for comparison. The red-shaded area represents the density at $4000 \mathrm{~K}$ with an error of $5 \%$ for possible uncertainties on the $\mathrm{SiO}_{2}$ thermal expansion [47]. 
using the thermal expansion coefficients from ab initio MD simulations [5]. The density difference between the $\mathrm{SiO}_{2}$ and $\mathrm{MgSiO}_{3}$ high-temperature isotherms at $4000 \mathrm{~K}$ is slightly larger than at room temperature, with a density difference of $\sim 4.0 \%$ at $60 \mathrm{GPa}$ that decreases to $\sim 1.3 \%$ at $140 \mathrm{GPa}$ (Fig. 3), although the thermal expansion can have some uncertainties too [47] (Fig. 3). This larger difference at high temperature results from different thermal expansivities for the two compositions and is in good agreement with ab initio calculations, that also found a higher density for $\mathrm{SiO}_{2}$ compared to $\mathrm{MgSiO}_{3}$ at high temperature [48]. Whereas $\mathrm{SiO}_{2}$ is the archetypal light component in silicate melts at crustal and upper mantle conditions and is responsible for the low density of granitic and other felsic melts, it is a more neutral to dense component for the buoyancy of silicate melts in the lower parts of the mantle.

For the pressure conditions of the deep mantle $(>90 \mathrm{GPa})$, the near identical densities of $\mathrm{SiO}_{2}$ and $\mathrm{MgSiO}_{3}$ melts suggest that $\mathrm{SiO}_{2}$ enrichment or depletion in the melt compared to the mineral phases will play a minor role in the final density evolution. It is expected that the $\mathrm{SiO}_{2}$ content of the melt will evolve with pressure in the lower mantle: the $\mathrm{SiO}_{2}$ content of the eutectic composition of a basaltic melt would rise from $64 \%$ at $26 \mathrm{GPa}$ up to $70 \%$ at the CMB [50], while the $\mathrm{SiO}_{2}$ content of a pyrolitic melt would decrease from $43 \%$ down to $40 \%$ for similar pressure [51]. However, such variations in the $\mathrm{SiO}_{2}$ fraction should at most have a minor effect on the final melt density. Second, because of the very small density contrast between ironfree compositions and their counterpart solid phases [Fig. 2(c), Fig. 3], the buoyancy of melts in the deep Earth will be mainly influenced by the addition of iron as the main heavy element. At the core-mantle boundary today, the density difference between the PREM model [52] and the iron-free melts is about 5\% (Fig. 3). In order for a silicate melt to be denser than the PREM model and buoyantly stable at the CMB today, the iron oxide content should be at least 25 mole \%, based on the density of $\mathrm{MgSiO}_{3}$ [30] and $\mathrm{FeO}$ [48] for a melt at $4000 \mathrm{~K}$. In the early Earth, the lower mantle must have been at a higher temperature, and both the solids and melts were at relatively similar temperatures. Thus, the density difference between the solid and the melt would have been less than it is today. Because iron is a less compatible element, it concentrates in the melts. Although the $\left.K_{D}\left(\left[\mathrm{Fe}^{\text {sol }}\right] /\left[\mathrm{Mg}^{\text {sol }}\right]\right) /\left(\left[\mathrm{Fe}^{\text {melt }}\right] /\left[\mathrm{Mg}^{\text {melt }}\right]\right)\right)$ value remains debated [53,54], the amount of iron in the melt, given by the partitioning of $\mathrm{Fe}\left(D_{\mathrm{Fe}}=\left[\mathrm{Fe}^{\mathrm{sol}}\right] /\left(\left[\mathrm{Fe}^{\text {melt }}\right]\right)\right.$, will be at least $50 \%$ [54] higher than in the solids. Therefore, the buoyancy of melts mainly depends on $P, T, X_{\mathrm{FeO}}$ and $K_{D}$ values. At CMB conditions, a melt will be buoyant for a bulk $\mathrm{FeO}>10 \%$ for any partitioning value measured experimentally [53-55] (Fig. S6). However, for lower $\mathrm{FeO}$ content, lower $K_{D}$ values are required and would considerably restrict the amount of melt present at the CMB. Thus, a basal magma ocean may have formed in the early Earth, but it strongly depends on the iron partitioning, the amount of $\mathrm{FeO}$ available, and its persistence through time also remains an open question.

In conclusion, our density data on $\mathrm{SiO}_{2}$ confirm the previous reported densities [8] as well as MD simulations [18]. As observed for $\mathrm{MgSiO}_{3}$ [30], amorphous $\mathrm{SiO}_{2}$ becomes nearly as dense, within a few percent, as the coexisting crystalline phases for pressures above $60 \mathrm{GPa}$. At pressures of the lower mantle (>80 GPa), the densities of $\mathrm{SiO}_{2}$ and $\mathrm{MgSiO}_{3}$ glasses are the same and at high temperature, the $\mathrm{SiO}_{2}$ melt is only slightly denser, within $2 \%$ to $4 \%$. Thus, variation of few percent of the $\mathrm{SiO}_{2}$ fraction in the melt composition [50,51] will have a minor effect on the final density of the melt at high pressure. The main parameter that controls the buoyancy of lower mantle melts is the iron content of the melt in comparison to that of the coexisting solids. Even a small excess of iron in the melt compared to the solids will lead to a density crossover and the accumulation of silicate melt on top of the core during the early Earth's formation [56]. These trapped melts, or their Fe-rich crystallization products, may explain large low-shear-velocity provinces and ultralow velocity zones above the CMB as detected today by seismic tomography, and constitute ideal candidates for pristine geochemical reservoirs in the deep mantle [57].

We are particularly grateful to $\mathrm{H}$. Shultz for the polishing of the starting samples prior to the beam time. We are thankful to M. Hanfland for the access and use of the offline Raman system of beam line ID15B. S. P. is grateful to $\mathrm{S}$. Pascarelli and R. Torchio for the loan of the portable ruby system of beam line ID24. D. Bugnazet and M. Salomé are thanked for their help in designing the sample holder for ID21 measurements. We acknowledge the ESRF for provision of beam time under the proposal ES-354 and ES-590. The two anonymous reviewers are also acknowledged for their fruitful comments. S. P. is financed by a DFG grant (PE 2334/1-1). S. P. and D. C. R are supported by the European Research Council (ERC) Advanced Grant "ACCRETE" (Contract No. 290568).

* Corresponding author.

Sylvain.Petitgirard@uni-bayreuth.de

[1] W. F. McDonough and S. S. Sun, Chem. Geol. 120, 223 (1995).

[2] C. Sanloup, J. W. Drewitt, Z. Konopkova, P. DalladaySimpson, D. M. Morton, N. Rai, W. VanWestrenen, and W. Morgenroth, Nature (London) 503, 104 (2013).

[3] M. Millot, N. Dubrovinskaia, A. Cernok, S. Blaha, L. Dubrovinsky, D. G. Braun, P. M. Celliers, G. W. Collins, J. H. Eggert, and R. Jeanloz, Science 347, 418 (2015).

[4] A. Zerr and R. Boehler, Nature (London) 371, 506 (1994).

[5] N. de Koker and L. Stixrude, Geophys. J. Int. 178, 162 (2009).

[6] W. J. Malfait, R. Seifert, S. Petitgirard, J.-P. Perrillat, M. Mezouar, T. Ota, E. Nakamura, P. Lerch, and C. SanchezValle, Nat. Geosci. 7, 122 (2014). 
[7] R. Seifert, W. J. Malfait, S. Petitgirard, and C. SanchezValle, Earth Planet. Sci. Lett. 381, 12 (2013).

[8] T. Sato and N. Funamori, Phys. Rev. Lett. 101, 255502 (2008).

[9] I. Farnan and J. F. Stebbins, Science 265, 1206 (1994).

[10] W. J. Malfait and W. E. Halter, Phys. Rev. B 77, 014201 (2008).

[11] C. T. Moyhihan, A. J. Easteal, J. Wilder, and J. Tucker, J. Phys. Chem. 78, 2673 (1974).

[12] M. L. Rivers and I. S. E. Carmichael, J. Geophys. Res. 92, 9247 (1987).

[13] R. Lange and I. S. E. Carmichael, Rev. Mineral. 24, 25 (1990).

[14] A. Polian, D. Vo-Thanh, and P. Richet, Europhys. Lett. 57, 375 (2002).

[15] C. Meade, R. J. Hemley, and H. K. Mao, Phys. Rev. Lett. 69 , 1387 (1992).

[16] C. J. Benmore, E. Soignard, S. A. Amin, M. Guthrie, S. D. Shastri, P. L. Lee, and J. L. Yarger, Phys. Rev. B 81, 054105 (2010).

[17] B. B. Karki, D. Bhattarai, and L. Stixrude, Phys. Rev. B 76, 104205 (2007).

[18] M. Wu, Y. Liang, J.-Z. Jiang, and J. S. Tse, Sci. Rep. 2, 398 (2012).

[19] G. Y. Shen, Q. Mei, V. B. Prakapenka, P. Lazor, S. Sinogeikin, Y. Meng, and C. Park, Proc. Natl. Acad. Sci. U.S.A. 108, 6004 (2011).

[20] T. Sato, N. Funamori, and T. Yagi, Nat. Commun. 2, 345 (2011).

[21] C. Weigel, A. Polian, M. Kint, B. Ruffle, M. Foret, and R. Vacher, Phys. Rev. Lett. 109, 245504 (2012).

[22] T. Deschamps, A. Kassir-Bodon, C. Sonneville, J. Margueritat, C. Martinet, D. de Ligny, A. Mermet, and B. Champagnon, J. Phys. Condens. Matter 25, 025402 (2013).

[23] P. W. Bridgman and I. Simon, J. Appl. Phys. 24, 405 (1953).

[24] J. D. Mackenzie and R. P. Laforce, Nature (London) 197, 480 (1963).

[25] S. Sugai and A. Onodera, Phys. Rev. Lett. 77, 4210 (1996).

[26] B. Champagnon, C. Martinet, M. Boudeulle, D. Vouagner, C. Coussa, T. Deschamps, and L. Grosvalet, J. Non-Cryst. Solids 354, 569 (2008).

[27] T. Deschamps, J. Margueritat, C. Martinet, A. Mermet, and B. Champagnon, Sci. Rep. 4, 7193 (2014).

[28] C. Meade and R. Jeanloz, Phys. Rev. B 35, 236 (1987).

[29] C. Meade and R. Jeanloz, Science 241, 1072 (1988).

[30] S. Petitgirard, W. J. Malfait, R. Sinmyo, I. Kupenko, L. Hennet, D. Harries, T. Dane, M. Burghammer, and D. C. Rubie, Proc. Natl. Acad. Sci. U.S.A. 112, 14186 (2015).

[31] M. Cotte et al., J. Anal. At. Spectrom. 32, 477 (2017).

[32] See Supplemental Material at http://link.aps.org/ supplemental/10.1103/PhysRevLett.119.215701 for a description of the sample and high-pressure techniques as well as measurement schemes on the beam lines. It shows an example of a high-pressure powder sample. The file also gives all the data from 0 to $110 \mathrm{GPa}$ and additional information about the equation of states fit. Finally it contains the results of melt buoyancy with various $\mathrm{FeO}$ content.

[33] I. Kantor, V. Prakapenka, A. Kantor, P. Dera, A. Kurnosov, S. Sinogeikin, N. Dubrovinskaia, and L. Dubrovinsky, Rev. Sci. Instrum. 83, 125102 (2012).

[34] H. K. Mao, J. Xu, and P. M. Bell, J. Geophys. Res. 91, 4673 (1986).

[35] Y. Akahama and H. Kawamura, J. Appl. Phys. 100, 043516 (2006).

[36] R. J. Angel, J. Gonzalez-Platas, and M. Alvaro, Z. Kristallogr. 229, 405 (2014).

[37] F. Birch, J. Geophys. Res. 83, 1257 (1978).

[38] D. Andrault, R. J. Angel, J. L. Mosenfelder, and T. Le Bihan, Am. Mineral. 88, 301 (2003).

[39] D. Andrault, R. G. Tronnes, Z. Konopkova, W. Morgenroth, H. P. Liermann, G. Morard, and M. Mezouar, Am. Mineral. 99, 2035 (2014).

[40] M. Murakami and J. D. Bass, Phys. Rev. Lett. 104, 025504 (2010).

[41] S. J. Gaudio, S. Sen, and C. E. Lesher, Geochim. Cosmochim. Acta 72, 1222 (2008).

[42] X. Xue, J. F. Stebbins, M. Kanzaki, P. F. McMillan, and B. Poe, Am. Mineral. 76, 8 (1991).

[43] T. Sato and N. Funamori, Phys. Rev. B 82, 184102 (2010).

[44] C. Prescher, V. B. Prakapenka, J. Stefanski, S. Jahn, L. B. Skinner, and Y. Wang, Proc. Natl. Acad. Sci. U.S.A. 114, 10041 (2017).

[45] A. N. Clark, C. E. Lesher, S. D. Jacobsen, and Y. Wang, J. Geophys. Res. 121, 4232 (2016).

[46] A. N. Clark, C. E. Lesher, S. D. Jacobsen, and S. Sen, Phys. Rev. B 90, 174110 (2014).

[47] N. de Koker and L. Stixrude, Geophys. J. Int. 183, 478 (2010).

[48] D. M. Ramo and L. Stixrude, Geophys. Res. Lett. 41, 4512 (2014).

[49] W. Xu, C. Lithgow-Bertelloni, L. Stixrude, and J. Ritsema, Earth Planet. Sci. Lett. 275, 70 (2008).

[50] N. de Koker, B. Karki, and L. Stixrude, Earth Planet. Sci. Lett. 361, 58 (2013).

[51] C. Liebske and D. J. Frost, Earth Planet. Sci. Lett. 345-348, 159 (2012).

[52] A. M. Dziewonski and D. L. Anderson, Phys. Earth Planet. Inter. 25, 297 (1981).

[53] R. Nomura, H. Oszawa, S. Tateno, K. Hirose, J. Hernlund, S. Muto, H. Ishii, and N. Hiraoka, Nature (London) 473, 199 (2011).

[54] D. Andrault, S. Petitgirard, G. Lo Nigro, J.-L. Devidal, G. Veronesi, G. Garbarino, and M. Mezouar, Nature (London) 487, 354 (2012).

[55] G. K. Pradhan, G. Fiquet, J. Siebert, A.-L. Auzende, G. Morard, D. Antonangeli, and G. Garbarino, Earth Planet. Sci. Lett. 431, 247 (2015).

[56] S. Labrosse, J. Hernlund, and N. Coltice, Nature (London) 450, 866 (2007).

[57] A. Caracausi, G. Avice, P. G. Burnard, E. Furi, and B. Marty, Nature (London) 533, 82 (2016). 